\title{
An Investigation of the Effect of Curcumin (Turmeric) Capsule on the Severity and Duration of Dysmenorrhea in Students of Iran University of Medical Sciences
}

\author{
Naghmeh Shahbaz Tabari ${ }^{1}$, Masoomeh Kheirkhah ${ }^{2}$, Faraz Mojab³ Masoud Salehi $^{4}$ \\ 1,2 Department of Midwifery and Reproductive Health, Nursing and Midwifery, Iran University of Medical \\ Sciences, Tehran, Iran. ${ }^{3}$ Department of Pharmacognosy, Shahid Beheshti University of Medical Sciences, \\ Tehran, Iran. ${ }^{4}$ Department of Biostatistics, Iran University of Medical Sciences, Tehran, Iran.
}

\section{ABSTRACT}

\section{BACKGROUND}

Dysmenorrhea is a very common and serious problem in women causing physical issues, mental issues and absence from social activities. Also, it is necessary to consider safety and side effects of new treatments. This study was designed to investigate the effect of curcumin (turmeric) capsule on severity and duration of dysmenorrhea.

\section{METHODS}

This study is a double blind randomized controlled clinical trial, conducted after obtaining informed consent form girls who were willing to participate in the study who complained of dysmenorrhea for the past 2 months. They were screened for two months and demographic questionnaire, menstrual characteristics, severity of dysmenorrhea were recorded. At the end of the two cycles, severity of their dysmenorrhea was marked by Verbal Multi-Dimensional Scoring, and those who had grade 2 dysmenorrhea based on the questionnaire enrolled to the study and were randomly assigned into two randomized blocks - curcumin group and placebo group. By considering $0.05 \%$ type I error, Type II error $\beta=0.2$ and the observed mean difference of 1.2 from a previous study, 37 subjects were included in each group. Intervention group curcumin containing $500 \mathrm{mg}$ turmeric extract made by Karen Pharmaceutical Company with 2 capsules with food for the first three days of menstruation were used for two cycles and the placebo group consumed the drug capsule of the Shahid Beheshti University of Medical Sciences' School of Pharmacy containing 10 grams of corn starch, which appeared to be similar to the intervention group. The severity and duration of pain were recorded by visual analogue scale (VAS) by the students (self-report) before and 3 hours after the intervention in both successive cycles. Data analysis (descriptive and analytical) was performed using SPSS software version 16.

\section{RESULTS}

The mean of pain intensity score after intervention in the drug group was $4.6 \pm 1.5$ and in the placebo group was $5.8 \pm 1.82$. The mean of pain duration before taking the pill in the drug group was $5.408 \pm 3.001$ and in the placebo group was $0.725 \pm 0.04$; also three hours after taking the pill in the drug group it was $-5.017 \pm 2.294$ and in the placebo group was $0.614 \pm 0.99$, which indicates a significant difference between the two groups in terms of severity and duration of pain $(\mathrm{p}<0.001)$.

\section{CONCLUSIONS}

Curcumin is effective in reducing the pain caused by dysmenorrhea. It can be used as an herbal treatment to reduce the severity and duration of dysmenorrhea.

\section{KEY WORDS}

Severity, Duration, Pain, Dysmenorrhea, Curcumin, Capsule
Corresponding Author: Dr. Masoomeh Kheirkhah, Department of Midwifery and Reproductive Health, Nursing and Midwifery, Iran University of Medical Sciences, Tehran, Iran.

E-mail: kheirkhah.m@iums.ac.ir

DOI: 10.14260/jemds/2020/755

How to Cite This Article:

Tabari NS, Kheirkhah M, Mojab F, et al. An investigation of the effect of curcumin (turmeric) capsule on the severity and duration of dysmenorrhea in students of Iran university of medical sciences. I Evolution Med Dent Sci 2020;9(46):34443451, DOI: 10.14260/jemds/2020/755

Submission 31-01-2020,

Peer Review 01-10-2020,

Acceptance 07-10-2020,

Published 16-11-2020.

Copyright (C) 2020 JEMDS. This is an open access article distributed under Creative Commons Attribution License [Attribution 4.0 International (CC BY 4.0)] 


\section{BACKGROUND}

Primary dysmenorrhea is one of the most prevalent and important complaints of women in the reproductive age. ${ }^{1}$ In primary dysmenorrhea, pain usually begins a few hours before or just after menstruation and takes about $48-72$ hours. $^{2} 75$ $\%$ of women experience dysmenorrhea during menstrual period; it usually begins before the age of 20,3 and almost three years after menarche. ${ }^{4}$ Its prevalence is about $72 \%$ in Iran, and about $20-90 \%$ in the world, 5 and it is the reason of $15 \%$ of girls referring to medical centers. ${ }^{6}$ Primary dysmenorrhea can be accompanied by nausea, vomiting, headache, fatigue, and backache. ${ }^{7}$

The secretion of prostaglandins into the uterine tissue, especially in the anti-inflammatory mediators such as PGF2 and PGE2 plays a major role in uterine contractions. ${ }^{8}$ Primary dysmenorrhea is one of the cost burdens on households, ${ }^{9}$ it is the main reason for absence from work and school, it results in a loss of 600 million hours of work and 2 billion dollars in each year. ${ }^{10}$ It has a negative impact on individual and social behaviours and is one of the main causes of disruption in the quality of life ${ }^{11}$ and it increases the burden of treatment costs. ${ }^{12}$ Among the effective factors, premature menarche, duration of menstrual bleeding, high stress levels, smoking, alcohol, being less than 20 years old, physical inactivity, and depression could be named. ${ }^{13}$ The main goal of the treatment is pain relief, 14 in therapeutic procedures, oral contraceptives, non-steroidal anti-inflammatory drugs, calcium channel blockers, and progesterone are used.15 Surgery and complementary medicine are among other methods. ${ }^{16}$ The results of various studies on Satureja, Teucrium polium, thymes, and Echinophora platyloba in treating dysmenorrhea have determined that these herbal medicines have antispasmodic agents (anti-prostaglandins). ${ }^{17}$ Among other medicinal herbs turmeric is known in the treatment of dysmenorrhea. Turmeric is an herbaceous and perennial plant and a member of ginger family, 18 its main ingredient is cur cumin ${ }^{19}$ which is the reason for its yellow color. Turmeric is used as a substitute for steroid, natural anti-inflammatory, and antidepressant drugs and also to treat arthritis, reduce cholesterol, and heal wounds. ${ }^{20}$ The curcumin in turmeric applies its anti-inflammatory effects by inhibiting the synthesis of prostaglandins F2 \& E2, nuclear factor (NF-KB), and cyclooxygenases. ${ }^{21}$

Prevention and treatment of primary dysmenorrhea, screening, and prescription of complementary medicine are the duties of midwives, and according to the paragraph 2 of Midwifery Regulation passed,22 reducing treatment costs is through substitution of complementary medicine. Midwives are at the forefront of treatment and referral of patients. Investigation in this regard, due to the high prevalence of primary dysmenorrhea in Iran, the importance of relieving the pain, and reducing the costs and its economic and social burden, can be effective in decreasing the pain and absence from social activities as well as promoting the patients' quality of life.

\section{METHODS}

In this double blinded randomized controlled clinical trial, the researchers and subjects were not aware of the drug content. The research population is all female single students of Iran University of Medical Sciences with primary dysmenorrhea. After obtaining permission from the university Ethics Committee with the number IR. IUMS. FMD. REC. 1396. 9411373008 on $09 / 18 / 2017$ and obtaining letter of introduction from the Education Department and registration on the site of Iranian Registry of Clinical Trials no: IRCT20171031037146N1, by referring to the girls' classes of Iran University of Medical Sciences, after obtaining the permission of the authorities, the study started after introduction and stating the study objectives to the students. The girls who had complained of dysmenorrhea intermittent cramping pain during menstruation concentrated in the lower abdomen, usually in the suprapubic area, sometimes manifesting as groin or back pain ${ }^{23}$ It starts at or before menstruation and is usually accompanied by nausea, vomiting, sweating, tachycardia, diarrhea, lethargy, dizziness, tenderness to the touch of the breast. ${ }^{24}$ And on the first or second day of menstruation, menstruation is more intense and usually lasts 48 - 72 hours ${ }^{25}$ in the past two months and were willing to participate in the study were invited. Data collection tools included a demographic information registration form for demographic and menstrual characteristics. In addition, the ruler was a visual pain that the subject marked according to the amount of pain and the marked point on the ruler from the beginning of the ruler in centimeters was equal to the numerical score of pain of the research unit. Visual pain questionnaire has been confirmed by ${ }^{26}$ the validity of these questionnaires. Cronbach's $\alpha$ method was used to determine the scientific reliability of data collection tools. The validity of the visual analog pain scale has been confirmed by and its reliability with Cronbach's alpha coefficient equal to 0.862 .

Visual analogue questionnaire. The validity of this questionnaire was confirmed by content validity and the tool scientific reliability through Cronbach's alpha equal to 0.886 . Validity and reliability of a multidimensional speech pain questionnaire in a study by Amiri Farahani ${ }^{28}$ and Andersch for definitive diagnosis of dysmenorrhea, demographic characteristics questionnaire, menstrual features, and severity of dysmenorrhea were given to students who complained of dysmenorrhea in the last two months. The subjects were screened for two months and after the end of two cycles they were asked to mark the intensity of their dysmenorrhea by Verbal Multi-Dimensional Scoring (VMDS). ${ }^{29}$

In this system, the dysmenorrhea is divided into 4 degrees. Grade 0: No pain, grade 1: mild dysmenorrhea, in which a painkiller is rarely needed and it has no effect on physical activity, grade 2: moderate dysmenorrhea which affects the individual's daily activities, but is relieved by a painkiller, and the third grade: severe dysmenorrhea, which rarely responds to painkillers, and there are some systemic symptoms observed such as nausea, vomiting, diarrhoea, and weakness. The researcher selected the subjects from those who had grade two and three dysmenorrhea according to the questionnaire. 


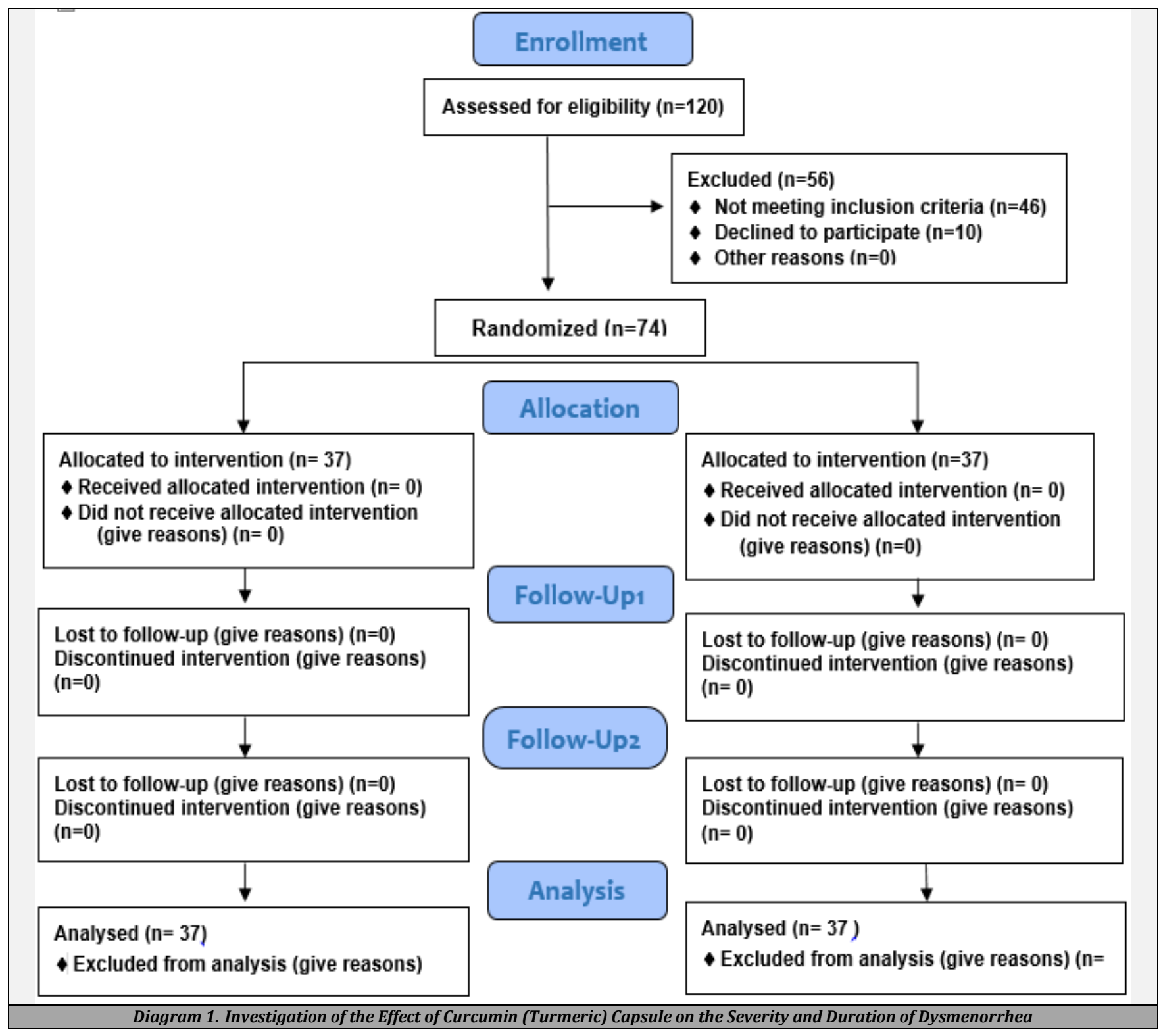

The sample size was selected according to the study of Jaafarpour, 2015 et al., which investigated the effect of cinnamon on primary dysmenorrhea, standard deviation of VAS in placebo (capsule containing $400 \mathrm{mg}$ Ibuprofen), TDS and intervention groups were obtained 1.9 and 1.6, respectively by considering the type I error $\alpha=0.05$, Type II error $\beta=0.2$ and mean difference $d=$ the minimum of the mean difference of VAS between the groups which showed a significant difference and was obtained 1.2 in the study. Therefore, thirty-seven individuals in each group were determined with a probability of $10 \%$ drop in sample size

$\hat{\mathrm{n}}=\frac{\left(\mathrm{z}_{1-\frac{\alpha}{2}}+\mathrm{z}_{1-\beta}\right)^{2}\left(\sigma_{1}^{2}+\sigma_{2}^{2}\right)}{\mathrm{d}^{2}} \cong 37$

$\mathrm{Z}_{0.95}=1.96$

$\mathrm{Z}_{0.8}=0.84$

$\mathrm{n}=\frac{(1.96+0.84)^{2}(1.9+1.6) 2}{(1.2)^{2}} \cong 37$
The informed consent form and demographic information were completed by the students. The inclusion criteria were symptoms of moderate and severe dysmenorrhea, 18 - 25 years of age, regular menstrual cycle, primary dysmenorrhea, no chronic mental illnesses, and no allergy to turmeric. Exclusion criteria included abnormal haemorrhage during the study, use of oral contraceptive drugs, using pain sedatives and other non-drug procedures during the study, severe psychiatric stress during the study, and occurrence of any allergic reaction to the curcumin capsule during the study.

The qualified subjects are fully described with the procedures. Early student by the VMDS questionnaire in terms of pain severity, the two groups were reassessed. Students were randomly included in-two in one of the two groups of $A$ and B. After two months of qualifying students with the inclusion criteria and determining the list of students with dysmenorrhea, each student was given a number according to the list of eligible students participating in the study and provide a random list for two groups from Sealed Envelope site. ${ }^{30}$ We used the Sealed Envelope site to provide randomization list. A list of blocks size 4 with random sequence of groups within each block generate randomly and 
saved to look up the treatment group for the given code. An eligible girls based on this random list, assigned to the control (placebo group) and intervention (curcumin group) groups.

This study was tripple-blinded; participants, researchers, and data analysts were blind during the study and the study samples were identified by the researcher and statistician only with the code given based on the site randomization list. To ensure blinding the coded list of the participants left behind the study manager until the end of clinical evaluation and data analysis. Participants in both the intervention and control groups received quite similar capsules made by pharmacist of Shahid Beheshti University of Medical Sciences with labels A and $\mathrm{B}$. Therefore, both the researchers and the participants were not aware of the interventions. In addition, the data analyst received the data with labels $\mathrm{A}$ and $\mathrm{B}$ for the treatment grouping variable.

The researcher's full name and telephone number was provided to the subjects to inform the researcher in case of a problem or any question. All the subjects were asked to record the duration and severity of pain in each cycle using the pain record checklist and the visual analogue of pain before and three hours after taking the medication (the peak effect of the drug is 3 hours and 30 minutes and the half-life of cur cumin is 7 hours) to the first three days of menstruation (regarding the fact that most of the inflammatory mediators such as prostaglandins and leukotrienes are produced in the first three days of menstruation and the greatest pain is induced during this period). During the study the subjects were followed up by phone calls. The intervention group treated with curcumin capsule (turmeric extract, daily dose limit of 3 g), each containing $500 \mathrm{mg}$ of turmeric extract based on 5.47 mg curcumin made by the Karen Pharmaceutical Company, with the license number of 1058067011726337 in the Food and Drug Administration, took 2 capsules with meal in the first 3 days of menstruation for 2 months. During this period, the control group with the same condition received placebo capsules prepared by the pharmacist of Shahid Beheshti University of Medical Sciences. The placebo contained corn starch and had 10 grams of carbohydrates and it looked like the original drug. The drugs administration continued for two menstruation cycles and at the end of each cycle, the use of the medication and its effect on the symptom relief were assessed through a visual analogue questionnaire. The validity of this questionnaire was confirmed by content validity and the tool scientific reliability through Cronbach's alpha equal to $0.886 .{ }^{31}$

The mean of the symptoms severity of dysmenorrhea was compared one month after the intervention with the control group. The probable side effects of the drug were described and the subjects were asked to inform the researcher in case of any complications.

\section{Statistical Analysis}

Data were extracted and analysed by descriptive and analytical statistics using SPSS version 16. For normal distribution of data, the appropriate independent samples $\mathrm{T}$ test was used to compare mean response of pain severity and duration between two groups. To adjust these results of pain severity and duration based on the menstrual cycle and stage of the capsule consumption Generalized Estimable Equations (GEE) method was considered. A new method that considers correlation between repeated data is GEE. So, this method was used for analysing our study data. ${ }^{32}$ GEE models allow the dependent variable to have an abnormal distribution. In this method, the correlations of observations within an individual are modelled by assuming a hypothetical correlation structure. The parameter estimation efficiency is affected by the type of correlation structure. Therefore, to improve the parameter estimation efficiency, the GEE method was used,

Chi square or fisher exact tests were used to compare distribution of qualitative variables between two groups. $\mathrm{P}$ values less than 0.05 were considered as significant.

\section{RESULTS}

Out of 74 subjects, 37 received curcumin capsules and 37 others received placebo capsules; finally, 74 subjects were analysed. Table 1 shows the distribution of different characteristics of the participants in both groups.

As shown in Table 1, distribution of baseline variables was not statistically significant between two groups $(\mathrm{p}>0.05)$. Table 2 displays the mean and standard deviation of pain severity and duration for both of the study groups.

Results of independent samples t-test shown in Table 2, revealed that mean of the pain duration were statistically lower in drug group compared to the placebo group in each stage of the study $(\mathrm{p}<0.001)$. Also, for the first cycle, 3 hours after consumption of placebo or drug pain severity was statistically lower in drug group compared to the placebo group ( $p=0.004)$. While, before consumption for the first cycle the pain severity was not statistically different between two groups ( $p=0.052$ ).

\begin{tabular}{|c|c|c|c|c|c|c|}
\hline \multirow[t]{2}{*}{ Variable } & \multirow[t]{2}{*}{ Level } & \multicolumn{2}{|c|}{ Intervention } & \multicolumn{2}{|c|}{ Placebo } & \multirow{2}{*}{ P-Value } \\
\hline & & No. & $\%$ & No. & $\%$ & \\
\hline Age (year) & $18-25$ & 29 & 78.4 & 29 & 78.4 & 1.00 \\
\hline Age (year) & $25-35$ & 8 & 21.6 & 8 & 21.6 & \\
\hline & $\mathrm{PhD}$ & 14 & 42.4 & 16 & 45.7 & \\
\hline Education Level & $\begin{array}{l}\text { Bachelor } \\
\text { MA }\end{array}$ & $\begin{array}{l}9 \\
7\end{array}$ & $\begin{array}{l}25.7 \\
21.2\end{array}$ & $\begin{array}{c}12 \\
9\end{array}$ & $\begin{array}{l}36.4 \\
25.7\end{array}$ & 0.343 \\
\hline $\begin{array}{c}\text { Father's } \\
\text { Occupational Status }\end{array}$ & Azad & 16 & 43.2 & 13 & 35.1 & 0.403 \\
\hline & $\begin{array}{c}\text { Clerk } \\
\text { Retired } \\
\text { Doctor } \\
\text { Lower }\end{array}$ & $\begin{array}{c}7 \\
11 \\
3 \\
3\end{array}$ & $\begin{array}{c}18.9 \\
29.7 \\
8.1 \\
8.1\end{array}$ & $\begin{array}{c}10 \\
9 \\
2 \\
0\end{array}$ & $\begin{array}{c}27 \\
24.3 \\
5.4 \\
0.0\end{array}$ & \\
\hline Economic Status & $\begin{array}{l}\text { Moderate } \\
\text { and low } \\
\text { Good }\end{array}$ & $\begin{array}{l}23 \\
13\end{array}$ & $\begin{array}{c}63 / 9 \\
36.1\end{array}$ & $\begin{array}{l}21 \\
15\end{array}$ & $\begin{array}{l}56.8 \\
40.5\end{array}$ & 0.721 \\
\hline Menarche Age & $\begin{array}{c}\geq 11 \\
11-13\end{array}$ & $\begin{array}{c}2 \\
21\end{array}$ & $\begin{array}{c}5.4 \\
56.8\end{array}$ & $\begin{array}{c}4 \\
15\end{array}$ & $\begin{array}{l}10.8 \\
40.5\end{array}$ & \\
\hline (Year) & $\begin{array}{c}13-17 \\
\geq 17\end{array}$ & $\begin{array}{c}13 \\
1\end{array}$ & $\begin{array}{c}35.1 \\
2.7\end{array}$ & $\begin{array}{c}18 \\
0\end{array}$ & $\begin{array}{c}48.6 \\
0.0\end{array}$ & 0.352 \\
\hline $\begin{array}{l}\text { The Start of } \\
\text { Menstruation }\end{array}$ & $\begin{array}{c}\text { A week ago } \\
2 \text { days ago } \\
1-3 \text { day } \\
\text { After } 3 \\
\text { days } \\
\text { Variable }\end{array}$ & $\begin{array}{c}1 \\
11 \\
22 \\
3 \\
0\end{array}$ & $\begin{array}{c}2.7 \\
29.7 \\
59.5 \\
8.1 \\
0.0\end{array}$ & $\begin{array}{c}0 \\
11 \\
24 \\
1 \\
1\end{array}$ & $\begin{array}{c}0.0 \\
29.7 \\
64.9 \\
2.7 \\
2.7\end{array}$ & 0.683 \\
\hline $\begin{array}{l}\text { The Highest } \\
\text { Distribution of } \\
\text { Menstrual Time }\end{array}$ & $\begin{array}{c}\geq 1 \\
1-2 \text { day } \\
>2\end{array}$ & $\begin{array}{c}9 \\
20 \\
8\end{array}$ & $\begin{array}{l}24.3 \\
54.1 \\
21.6\end{array}$ & $\begin{array}{c}6 \\
23 \\
8\end{array}$ & $\begin{array}{l}16.2 \\
62.2 \\
21.6\end{array}$ & 0.668 \\
\hline $\begin{array}{l}\text { History of Not Using } \\
\text { Herbal Medicines }\end{array}$ & $\begin{array}{l}\text { No } \\
\text { Yes }\end{array}$ & $\begin{array}{l}20 \\
16\end{array}$ & $\begin{array}{l}55.6 \\
44.4\end{array}$ & $\begin{array}{l}24 \\
13\end{array}$ & $\begin{array}{l}64.9 \\
35.1\end{array}$ & 0.416 \\
\hline $\begin{array}{l}\text { Family History of } \\
\text { Pain in the } \\
\text { Menstrual Cycle }\end{array}$ & $\begin{array}{l}\text { Yes } \\
\text { No }\end{array}$ & $\begin{array}{c}39 \\
5\end{array}$ & $\begin{array}{l}85.3 \\
14.7\end{array}$ & $\begin{array}{c}27 \\
9\end{array}$ & $\begin{array}{l}75 \\
25\end{array}$ & 0.282 \\
\hline
\end{tabular}

In table 2 placebo and intervention are the names of two group columns, mean and SD for both group in the sun-column name, and finally row contains of variables name, therefor in the first row one can find the mean and SD for VAS provide for both groups. Results of GEE models are reported in table 3. 


\begin{tabular}{|c|c|c|c|c|c|c|c|}
\hline \multirow[t]{2}{*}{ Variables } & \multirow[t]{2}{*}{ Cycle } & \multirow[t]{2}{*}{ Stage } & \multicolumn{2}{|c|}{ Placebo } & \multicolumn{2}{|c|}{ Drug } & \multirow[t]{2}{*}{$\begin{array}{c}\text { P- } \\
\text { Value }\end{array}$} \\
\hline & & & Mean & SD & Mean & SD & \\
\hline \multirow[t]{2}{*}{$\begin{array}{l}\text { VAS Pain } \\
\text { Severity }\end{array}$} & First & Before consumption & 6.4 & 1.72 & 5.7 & 1.52 & 0.052 \\
\hline & & $\begin{array}{l}3 \text { hours after } \\
\text { consumption }\end{array}$ & 5.8 & 1.82 & 4.6 & 1.50 & 0.004 \\
\hline \multirow[t]{2}{*}{ Pain Duration } & First & Before consumption & 31.5 & 18.00 & 10.6 & 15.23 & $<0.001$ \\
\hline & & $\begin{array}{l}3 \text { hours after } \\
\text { consumption }\end{array}$ & 18.6 & 11.66 & 7.4 & 9.43 & $<0.001$ \\
\hline \multirow[t]{2}{*}{ Pain Duration } & Second & Before consumption & 30.2 & 21.17 & 12.00 & 22.39 & $<0.001$ \\
\hline & & $\begin{array}{l}3 \text { hours after } \\
\text { consumption }\end{array}$ & 16.9 & 11.85 & 9.9 & 18.26 & $<0.001$ \\
\hline
\end{tabular}

\begin{tabular}{|cccccccc|}
\hline Model Response & Parameter Estimation St. E. & $\begin{array}{c}95 \% \text { CI } \\
\text { Lower }\end{array}$ & $\begin{array}{c}\text { P- } \\
\text { Upper }\end{array}$ & Value \\
Model 1 & $\begin{array}{c}\text { Pain VAS } \\
\text { severity }\end{array}$ & Group & 0.98 & 0.35 & 1.67 & 7.66 & 0.006 \\
& Stage & 0.76 & 0.16 & 0.43 & 1.08 & $<0.001$ \\
Model 2 & & & & & & \\
Pain duration & Group & 14.39 & 3.2 & 8.12 & 20.67 & $<0.001$ \\
& Stage & -0.16 & 1.77 & -3.63 & 3.32 & 0.929 \\
& Cycle & 8.01 & 1.27 & 5.52 & 10.50 & $<0.001$ \\
\hline \multicolumn{2}{|c|}{ Table 3. Results of GEE Models for Pain Severity and Duration } \\
\hline
\end{tabular}

As one can see in Table 3, in the model 1 pain severity will grow in placebo group compared with intervention group. In other words, after adjusting for stage (before and after of consumption) pain severity in placebo group is about one score more than intervention group $(p=0.006)$. Also, in the second model pain duration will grow about 15 minutes in the placebo group compared to the intervention group $(\mathrm{p}<0.001)$.

\section{DISCUSSION}

Considering the fact that general objective of the present study is to investigate the effect of curcumin (turmeric) capsule on the severity and duration of dysmenorrhea on the students of Iran University of Medical Sciences, associated studies related to the current study are compared.

Lone et al. (2018) conducted a randomized clinical trial with the purpose of determining the role of turmeric on alveolar osteitis. All of the symptoms in group A (intervention) such as pain, swelling with mean and standard deviation of $1.47 \pm 0.30$ and in group B (control) with a mean and standard deviation of $1.98 \pm 0.49(p \leq 0.05)$ have decreased. ${ }^{33}$

Kawasaki et al. (2017) also conducted a randomized clinical trial with the objective of investigating the effects of combination of curcumin and extracellular extracts of curcuma on inflammatory factors, emotional state, and liver enzymes of the subjects with moderate body mass index. Results indicated that curcumin reduces inflammatory factors. ${ }^{34}$ Daily et al. (2016) carried out a randomized clinical trial study to determine the effect of turmeric capsule (curcumin) on the reduction of arthritis symptoms in the elderly. Symptoms such as pain, sensitivity to touch, inflammation, and dryness of the joints have shown to decrease compared to routine treatments. ${ }^{35}$

McFarlin et al. (2016) conducted a cross-sectional study to determine the effectiveness of curcumin capsules in reducing inflammation in a damaged muscle. The results indicated a decrease in the level of creatinine kinase, interleukin 8 , and necrosis factor of alpha tumour in the curcumin group four days after receiving the drug in comparison with placebo $(\mathrm{p} \leq$ 0 / 05). ${ }^{36}$

The results of a study by Nakagawa et al. (2014), with the objective to determine the short-term effectiveness of curcumin in the treatment of knee osteoarthritis, indicated that curcumin was more effective in soothing the pain associated with osteoarthritis than the placebo group. ${ }^{37}$

Klawitter et al. (2012) conducted a study to investigate the effect of turmeric extract on the cells of damaged intervertebral discs. After 6, 18, and 30 hours, data analysis indicated that turmeric extract reduced the level of interleukin 6 and MMP $(\mathrm{P} \leq 0 / 005){ }^{38}$

Hosseini et al. (2012) also examined the effect of turmeric powder diet on reducing the oxidative stress caused by heat stress in chickens. The results indicated that not changing in the levels of triglyceride and total cholesterol were due to experimental diets, but serum LDL amount in the group feeding with $0.4 \%$ turmeric was lower compared to the main group. HDL level increased under the effect of turmeric powder in comparison with the main group and the level of glutathione peroxidase enzyme (GPx) in chickens fed with turmeric powder improved compared to the main group; however, it did not have a significant effect on the activity of superoxide dismutase (SOD). ${ }^{39}$

Kalvandi, et al. (2014) conducted a study to compare the effects of herbal medicines Dracocephalum and Common sage on primary dysmenorrhea. The results of this study indicated that the mean intensity of menstrual pain before and after using these herbs decreased to $3.94 \pm 2.07$ and $3.24 \pm 2.06$ in the first and second periods respectively; additionally, the maximum duration of menstrual pain before consumption was 1 to 6 hours, which decreased to less than 1 hour after treatment. The mean duration of bleeding before the use was $1.61 \pm 6.36$ days which decreased to $1.49 \pm 6.48$ and $1.87 \pm$ 6.34 after the use in the first and second period respectively $\mathrm{p}$ $\leq 0.05 .10$

The results of a study by Kheirkhah et al. (2015), which aimed to investigate the effect of curcumin on the symptoms of premenstrual syndrome, indicated that the mean scores of PMS (Pre-Menstrual Syndrome) symptoms after 1, 2, and 3 cycles of intervention were significantly different $(\mathrm{p} \leq$ 0.0001).40,41

\section{CONCLUSIONS}

According to the results of the present study, alongside the studies conducted in the world indicating the effectiveness of curcumin (turmeric) in the treatment of inflammatory and analgesic diseases, and due to the fact that significant side effects of oral intake of turmeric (curcumin) in the treatment of inflammatory diseases like osteoarthritis, etc. were not observed in various individuals of the society, this treatment can be recommended as an accessible, easy, and inexpensive method for most women in the society along with commonly used treatments. This will increase the choice of individuals in the treatment of dysmenorrhea and the side effect of existing chemical treatments can be eliminated.

Data sharing statement provided by the authors is available with the full text of this article at jemds.com.

Financial or other competing interests: None. 
Disclosure forms provided by the authors are available with the full text of this article at jemds.com.

The present study with the number 9411373008 was a dissertation project conducted to obtain a Master degree in midwifery from Iran University of Medical Sciences. Hereby, I appreciate and thank the Postgraduate Department and Vice Presidency of Education of Iran University of Medical Sciences and all the individuals who participated in this research.

\section{REFERENCES}

[1] Abd-El-Maeboud KHI, Kortam MAM, Ali MS, Ibrahim MI, et al. A preliminary pilot randomized crossover study of uzara (Xysmalobium undulatum) versus ibuprofen in the treatment of primary dysmenorrhea. PLoS One 2014;9(8):e104473.

[2] Berkley K, McAllister SL. Don't dismiss dysmenorrhea. Pain 2011;152(9):1940-1.

[3] Cunningham FG, Leveno KJ, Bloom SL et al. Williams obstetrics. 23rd edn. New York: McGraw-Hill 2010:684-6.

[4] Wong LP. Attitudes towards dysmenorrhea, impact and treatment seeking among adolescent girls: a rural schoolbased survey. Aust J Rural Health 2011;19(4):218-23.

[5] Latthe PM, Champaneria R, Khan KS. Dysmenorrhea. BMJ Clin Evid 2011;2011:0813.

[6] Speroff L, Fritz MA. Clinical gynecologic endocrinology and infertility. Lippincott Williams \& Wilkins 2005.

[7] Ortiz MI. Primary dysmenorrhea among Mexican university students: prevalence, impact and treatment. Eur J Obstet Gynecol Reprod Biol 2010;152(1):73-7.

[8] Maybin JA, Critchley HOD, Jabbour HN. Inflammatory pathways in endometrial disorders. Mol Cell Endocrinol 2011;335(1):42-51.

[9] Ozerdogan N, Sayiner D, Ayranci U, et al. Prevalence and predictors of dysmenorrhea among students at a university in Turkey. Int J Gynaecol Obstet 2009;107(1):39-43.

[10] Kalvandi R, Alimohammadi SH, Pashmakian Z, et al. The Effects of Medicinal Plants of Melissa officinalis and Salvia officinalis on Primary Dysmenorrhea. Scientific Journal of Hamadan University of Medical Sciences 2014;21(2):10511.

[11] Vincent K, Warnaby C, Stagg CJ, et al. Dysmenorrhea is associated with central changes in otherwise healthy women. Pain 2011;152(9):1966-75.

[12] Zahradnik HP, Hanjalic-Beck A, Groth K. Nonsteroidal anti-inflammatory drugs and hormonal contraceptives for pain relief from dysmenorrhea: a review. Contraception 2010;8(3):185-19.

[13] Faramarzi M, Salmalian H. Association of psychological factors with primary dysmenorrhea. Iran Red Crescent Med J 2014;16(8):e16307.

[14] Osayande AS, Mehulic S. Diagnosis and initial management of dysmenorrhea. Am Fam Physician 2014;89(5):341-6.

[15] Johnston L. Menstrual pain (dysmenorrhea). Profession Nurs Today 2014;18(1):4-13.

[16] Moher D, Shamseer L, Clarke M, et al. Preferred reporting items for systematic review and meta-analysis protocols (PRISMA-P). Syst Rev 2015;4(1):1.

[17] Janabi E, Ibrahimzadeh S. Effect of Recucita tea on first dysmenorrhea. J Obstet Gynecol Infer 2010;13(1):39.
[18] Gupta SC, Kismali G, Aggarwal BB. Curcumin, a component of turmeric: from farm to pharmacy. Biofactors 2013;39(1):2-13.

[19] Jurenka JS. Anti-inflammatory properties of curcumin, a major constituent of Curcuma longa: a review of preclinical and clinical research. Altern Med Rev 2009;14(2):141-53.

[20] Buyuklu M, Kandemir FM, Ozkaraca M, et al. Protective effect of curcumin against contrast induced nephropathy in rat kidney: what is happening to oxidative stress, inflammation, autophagy and apoptosis? Eur Rev Med Pharmacol Sci 2014;18(4):461-70.

[21] Burtis CA, Ashwood ER Bruns DE. Tietz textbook of clinical chemistry and molecular diagnostics. Elsevier Health Science 2012.

[22] Pazandeh F, Afshari P, Kord M. Study of awareness and performance of ahvazi midwives about physiologic childbirth in public hospitals, 2016. Advances in Nursing \& Midwifery 2018;27(3):35-8.

[23] Fritz M, El Rawas R, Salti A, et al. Reversal of cocaineconditioned place preference and mesocorticolimbic Zif268 expression by social interaction in rats. Addict Biol 2011;16(2):273-84.

[24] Goodwin TM, Montoro MN, Muderspach L, et al. Management of common problems in obstetrics and gynecology. John Wiley \& Sons 2010.

[25] Simillis C, Jacovides M, Reese GE, et al. Meta-analysis of the role of granulomas in the recurrence of Crohn disease. Dis Colon Rectum 2010;53(2):177-85.

[26] Gharloghi S, Torkzahrani S, Akbarzadeh AR, et al. The effects of acupressure on severity of primary dysmenorrhea. Patient Prefer Adherence 2012;6:137-42.

[27] Chia C, lai JHY, Cheung PK, et al. Dysmenorrhoea among Hong Kong university students: prevalence, impact, and management. Hong Kong Med J 2013;19(3):222-8.

[28] Andersch B, Milsom I. An epidemiologic study of young women with dysmenorrhea. Am J Obstet Gynecol 1982;144(6):655-60.

[29] Farahani LA, Heidari T, Roozbahani N, et al. Effect of aromatherapy on pain severity in primary dysmenorrhea. J Arak Uni Med Sci 2012;15(4):1-9.

[30] Jaafarpour M, Hatefi M, Najafi F, et al. The effect of cinnamon on menstrual bleeding and systemic symptoms with primary dysmenorrhea. Iran Red Crescent Med J 2015;17(4):e27032.

[31] Sealed Envelope Ltd. 2019. Simple randomisation service. https://www.sealedenvelope.com/simplerandomiser/v1/

[32] Fitzmaurice G, Laird N, Ware J. Applied longitudinal analysis. $2^{\text {nd }}$ edn. John Wiley \& Sons 2011.

[33] Lone PA, Ahmed SW, Prasad V, et al. Role of turmeric in management of alveolar osteitis (dry socket): a randomized clinical study. J Oral Biol Craniofac Res 2018;8(1):44-7.

[34] Kawasaki K, Muroyama K, Fukuhara I, et al. Effect of a combination of hot water extract of curcuma longa and curcumin on serum liver enzymes, inflammatory markers, and emotional states in healthy participants with moderately high body mass index -a randomized, double-blind, placebo-controlled clinical trial. J pn Pharmaco 2017;45(2):23-9.

[35] Daily JW, Yang M, Park S. Efficacy of turmeric extracts and curcumin for alleviating the symptoms of joint arthritis: a 
systematic review and meta-analysis of randomized clinical trials. J Med Food 2016;19(8):717-29.

[36] McFarlin BK, Venable AS, Henning AL et al. Reduced inflammatory and muscle damage biomarkers following oral supplementation with bioavailable curcumin. BBA Clin 2016;5:72-8.

[37] Nakagawa Y, Mukai S, Yamada S, et al. Short-term effects of highly-bioavailable curcumin for treating knee osteoarthritis: a randomized, double-blind, placebocontrolled prospective study. J Orthop Sci 2014;19(6):933-9.

[38] Klawitter M, Quero L, Klasen J, et al. Curcuma DMSO extracts and curcumin exhibit an anti-inflammatory and anti-catabolic effect on human intervertebral disc cells, possibly by influenting TLR2 expression and JNK activity. J Inflamm (Lond) 2012;9(1):29.

[39] Vannabhum M, Poopong S, Wongwananuruk T, et al. The efficacy of Thai herbal Prasaplai formula for treatment of primary dysmenorrhea: a short-term randomized controlled trial. Evid Based Complement Alternat Med 2016;2016:2096797.

[40] Hosseini V, Yaghoubfar A, Gilan A, et al. The effect of turmeric powder diet on reducing the oxidative stress caused by heat stress in chickens. Journal of Birjand University of Medical Sciences 2012;19(2):157-64.

[41] Khayat S, Fanaei $H$, Kheirkhah $M$, et al. The effect of curcumin on premenstrual syndrome symptoms: a double-blind randomized clinical trial. Nurs Midwifery J 2016;13(11):935-44. 